\title{
Ultrapotent and Broad Neutralization of SARS-CoV-2 Variants by Modular, Tetravalent, Bi-paratopic Antibodies
}

Shane Miersch ${ }^{1}$, Reza Saberianfar ${ }^{1}$, Chao Chen $^{1}$, Nitin Sharma ${ }^{2}$, Gaya K. Amarasinghe ${ }^{2}$, Francesca Caccuri ${ }^{3}$, Alberto Zani ${ }^{3}$, Arnaldo Caruso ${ }^{3}$, Giuseppe Novelli ${ }^{4,5,6}$, Sachdev S Sidhu ${ }^{1 *}$

${ }^{1}$ The Donnelly Centre, University of Toronto, Toronto, Canada

${ }^{2}$ Department of Pathology and Immunology, Washington University School of Medicine, Saint Louis, MO, USA

${ }^{3}$ Section of Microbiology, Department of Molecular and Translational Medicine, University of Brescia Medical School, 25123 Brescia, Italy

${ }^{4}$ Department of Biomedicine and Prevention, University of Rome Tor Vergata, Via Montpellier

1, 00133, Rome, 6 Italy

${ }^{5}$ IRCCS Neuromed, Pozzilli (IS), Italy 15

${ }^{6}$ Department of Pharmacology, School of Medicine, University of Nevada, Reno, NV 89557, USA

* - Corresponding author

Corresponding authors email: sachdev.sidhu@utoronto.ca

\section{Keywords}

Antibody, SARS-CoV-2, neutralization, passive immunotherapy, bi-specific, bi-paratopic, virus variant, $\mathrm{S}$ protein, RBD, mutational escape 


\section{Summary}

Neutralizing antibodies (nAbs) that target the SARS-CoV-2 spike protein are approved for treatment of COVID-19. However, with the emergence of variants of concern, there is a need for new treatment options. We report a novel format that enables modular assembly of bi-paratopic, tetravalent nAbs with antigen-binding sites from two distinct nAbs. The tetravalent nAb was purified in high yield, and it exhibited biophysical characteristics that were comparable to those of approved therapeutic antibodies. The tetravalent $\mathrm{nAb}$ bound to the spike protein trimer at least 100-fold more tightly than bivalent IgGs (apparent $\mathrm{K}_{\mathrm{D}}<1 \mathrm{pM}$ ), and it exhibited extremely high potencies against a broad array of pseudoviruses, chimeric viruses, and authentic virus variants. Together, these results establish the tetravalent diabody-Fc-Fab as a robust, modular platform for rapid production of drug-grade nAbs with potencies and breadth of coverage that greatly exceed those of conventional bivalent IgGs.

\section{Introduction}

SARS-CoV-2, the causative agent of the ongoing COVID-19 pandemic, relies on its surface spike glycoprotein (S-protein) to mediate interaction with and entry into host cells (Hoffmann et al., 2020). The surface of the virus particle is studded with 25-100 copies of Sprotein homotrimers, and each S-protein consists of two subunits (Klein et al., 2020; Walls et al., 2020). The N-terminal subunit (S1) mediates host cell recognition, whereas the C-terminal subunit (S2) mediates membrane fusion and host cell entry. The S1 domain itself contains a distinct N-terminal domain (NTD) followed by a receptor-binding domain (RBD) that is responsible for host cell recognition through interactions with the human cell-surface protein angiotensin-converting enzyme 2 (ACE2).

Most of the natural neutralizing antibodies (nAbs) that arise in response to SARS-CoV-2 infection target the S1 subunit, and while the most potent of these bind to the RBD and compete with ACE2 (Brouwer et al., 2020; Garrett Rappazzo et al., 2021; Tortorici et al., 2020), other RBD-binding antibodies are also neutralizing (Pinto et al., 2020). Cloning and recombinant production of these natural nAbs has led to the development of several drugs that have proven successful for inhibiting virus replication in patients and have been approved for therapy (Gottlieb et al., 2021; Razonable et al., 2021). Structural studies have shown that the most potent neutralizing IgGs bind to epitopes that overlap with the ACE2 epitope and take advantage of 
their bivalent nature to achieve high affinity by binding simultaneously to two of the three RBDs within the S-protein trimer (Miersch et al., 2021; Yan et al., 2021).

However, despite the significant clinical success of bivalent nAbs for treatment of COVID-19, they suffer from two significant drawbacks. First, even nAbs that are highly potent in vitro must be administered at extremely high doses, presumably at least in part due to low penetrance of IgGs to sites within the lungs where SARS-CoV-2 infects and replicates (Hart et al., 2001). Second, approved IgG drugs that were derived from nAbs that arose in response to the original strain of the virus have proven to be ineffective against many variants of concern (VoCs) that have arisen since. Moreover, there is some evidence that single agent nAb therapy may promote evolution of resistant variants (Jensen et al., 2021; Weisblum et al., 2020). Notably, most VoCs that resist current therapeutic nAbs contain mutations within the RBD, which disrupt binding to nAbs but not to ACE2 (Greaney et al., 2021; McCallum et al., 2021; Planas et al., 2021; Zhou et al., 2021).

These limitations on potency and breadth of coverage appear to be inherent to singleagent $\mathrm{nAb}$ drugs, but several options for alleviating these problems have been explored. Cocktails of two nAbs, ideally with non-overlapping epitopes, have been shown to be more potent and resistant to virus escape, but the considerable complexity and expense of combining two nAbs makes this approach problematic (Baum et al., 2020; Hansen et al., 2020; Weinreich et al., 2021). Alternatively, small modular Ab variable domains or non-antibody scaffolds have been assembled as multimers that can simultaneously engage all three RBDs on an S-protein trimer and thus enhance potency beyond bivalent binding (Cao et al., 2020; Hunt et al., 2021; Kayabolen et al., 2021; Walser et al., 2021; Xu et al., 2021). In another approach, a bispecific, bivalent $\operatorname{IgG}$ - with each arm targeting a different epitope on the RBD - has been shown to neutralize VoCs that escape from conventional IgGs (de Gasparo et al., 2020).

We previously explored approaches that expand the valency of conventional bivalent IgGs without introducing non-Ab scaffolds that may compromise drug development due to issues of immunogenicity, developability, and/or manufacturing. We recently isolated a human nAb (15033) against SARS-CoV-2 from a synthetic phage-displayed library, and engineered a variant $\mathrm{nAb}$ (15033-7) with changes in the light chain that enhanced potency (Miersch et al., 2021). We then constructed tetravalent nAbs by fusing additional copies of the 15033-7 Fab to the $\mathrm{N}$ - or C-terminus of the 15033-7 IgG, and we showed that these tetravalent nAbs exhibited 
enhanced potency against an original SARS-CoV-2 isolate and an evolved VoC. Importantly, the tetravalent nAbs could be produced at high yields with the same methods used for bivalent IgGs, without compromising biophysical properties required for effective drug development.

We now report a novel tetravalent $\mathrm{Ab}$ format that expands on our earlier work and provides the significant advantage of enabling facile, modular assembly of tetravalent, biparatopic nAbs containing two distinct paratopes targeting the SARS-CoV-2 RBD. To achieve this, we first converted the 15033-7 IgG (Figure 1A) into a diabody-Fc format (D-Fc, Figure 1B) consisting of $\mathrm{VH}$ and VL domains linked together in a single polypeptide, and we showed that the new format was comparable to the $\mathrm{IgG}$ format in terms of production, affinity, and potency. The homodimeric D-Fc format enabled the facile fusion of Fab arms to the C-terminus to generate tetravalent diabody-Fc-Fab (D-Fc-F) molecules (Figure 1C). Because the diabody paratope does not require a separate light chain, this format proved to be highly modular, and Fabs could be added without any issues of the Fab light chain interfering with the diabody or vice versa. Thus, we could easily add either the 15033-7 Fab or the Fab from a different nAb 15036 to assemble either a mono-paratopic or a bi-paratopic tetravalent D-Fc-F molecule, respectively. The bi-paratopic D-Fc-F could be produced with yields and purities similar to those of conventional IgGs and exhibited excellent biophysical properties comparable to those of antibody drugs. It neutralized a panel of pseudoviruses representing diverse SARS-CoV-2 VoCs with potencies that greatly exceeded those of the component IgGs and proved to be highly potent even against variants that resisted the IgGs and the mono-paratopic D-Fc-F. Most importantly, neutralization of both chimeric and authentic live VoCs in two independent laboratories validated these findings, confirming both high potency and breadth of coverage.

\section{Results}

\section{Characterization of $\mathrm{Ab} 15036$}

To complement our previously characterized nAb 15033-7, we used well-established phage display methods with a highly validated synthetic human Fab-phage library (Persson et al., 2013) to identify a second Ab that bound to the RBD (see Materials and Methods). Ab 15036 had a very different paratope in comparison with 15033-7 (Figure 2A). Both Abs competed with each other for binding to immobilized RBD, as assessed by phage ELISAs in which binding of Fab- 
phage was measured in the presence or absence of saturating concentration of IgG protein (Figure 2B). However, whereas IgG 15033-7 completely blocked phage-displayed Fab 15036, IgG 15036 only partially blocked phage-displayed Fab 15033-7, suggesting that the epitopes for the two Fabs likely overlap to some extent but are not identical. Bilayer interferometry (BLI) assays showed that IgG 15036 bound to the S-protein trimer with a high affinity (apparent $\mathrm{K}_{\mathrm{D}}=$ $220 \mathrm{pM}$ ) that was comparable to the previously determined affinity of IgG 15033-7 (apparent $\mathrm{K}_{\mathrm{D}}$ $=70$ pM) (Figure 2C and Table 1) (Miersch et al., 2021). Taken together, these results showed that $\mathrm{Ab} 15036$ binds with high affinity to an epitope on the RBD that may overlap at least partially with the epitope of $\mathrm{Ab} 15033-7$, a potent $\mathrm{nAb}$ that competes with ACE2. Thus, Ab 15036 should also be a potent nAb for preventing SARS-CoV-2 infection, which we confirmed below.

\section{Characterization of D-Fc 15033-7}

We produced IgG (Figure 1A) and D-Fc (Figure 1B) versions of Ab 15033-7 by transient transfection of Expi293F cells and purified the proteins by protein-A affinity chromatography. Both proteins were purified in high yield (165 or $88 \mathrm{mg} / \mathrm{L}$ for the $\mathrm{IgG}$ or D-Fc, respectively) (Table 1). Moreover, both proteins were highly pure, as assessed by SDS-PAGE (Figure 3A). The gels showed single bands of the appropriate size for intact molecules under non-reducing conditions with intact intermolecular disulfide bonds, whereas under reducing conditions without disulfide bonds, they showed a heavy-chain band and a light-chain band for the IgG, or a single band for a D-Fc monomer. Size exclusion chromatography (SEC) revealed that the IgG eluted as a predominantly (95\%) monodisperse peak with an elution volume nearly identical to that of trastuzumab, whereas the D-Fc eluted as a predominantly (72\%) monodisperse peak that was slightly delayed compared with trastuzumab, consistent with its smaller molecular weight (Figure 3B). Affinity measurements by BLI showed that the IgG and D-Fc proteins bound with similar high affinities to the trimeric S-protein ECD (apparent $\mathrm{K}_{\mathrm{D}}=70$ or $160 \mathrm{pM}$, respectively) (Figure 3C and Table 1). Most importantly, in cell-based assays with a pseudovirus displaying the SARS-CoV-2 S-protein, the IgG and D-Fc proteins neutralized infection with essentially identical potencies $\left(\mathrm{IC}_{50}=29\right.$ or $30 \mathrm{ng} / \mathrm{mL}$, respectively) (Figure 3D). 


\section{Characterization of D-Fc-F proteins}

We constructed D-Fc-F proteins (Figure 1C) in which the Fab of either the 15033-7 or $15036 \mathrm{nAb}$ was fused to the C-terminus of D-Fc 15033-7. The resulting tetravalent molecules contained either four copies of the 15033-7 paratope (mono-paratopic, named D-Fc-F 33-7:33-7) or two copies of the 15033-7 paratope in the diabody head and two copies of the 15036 paratope in the Fab arms (bi-paratopic, named D-Fc-F 33-7:36). D-Fc-F 33-7:33-7 and 33-7:36 were both purified in similar high yields (190 or $189 \mathrm{mg} / \mathrm{L}$, respectively) to high purity as evidenced by SDS-PAGE (Figure 4A, Table 1), with the same methods used for purification of IgG and D-Fc proteins. In gel filtration SEC, both proteins exhibited a predominant monodisperse peak $(80 \%$ and $81 \%$ for D-Fc-F 33-7:33-7 or 33-7:36, respectively) that eluted earlier than the $\operatorname{IgG}$ trastuzumab, consistent with the larger size of the D-Fc-F protein (Figure 4B and Table 1). BLI analysis with trimeric S-protein ECD showed that D-Fc-F proteins bound very tightly and exhibited extremely slow off-rates that were beyond the dynamic range of the instrument, and consequently, apparent dissociation constants could not be measured accurately but were in the sub-picomolar range (apparent $\left.\mathrm{K}_{\mathrm{D}}<1 \mathrm{pM}\right)$ (Figure 4C and Table 1).

\section{Inhibition of virus infection in cell-based assays}

To explore and compare the efficacy of the D-Fc-F proteins and their component $\mathrm{IgG}$ proteins for neutralization of SARS-CoV-2 VoCs, we first used mammalian cell infection assays with pseudoviruses consisting of HIV-gag-based, lentivirus-like particles pseudotyped with various SARS-CoV-2 S-proteins (Connor et al., 1995). We used a panel of seven pseudoviruses based on the S-protein of an early "wild-type" (WT) SARS-CoV-2 isolated in Washington (strain 2019 n-CoV/USA_WA1/2020) modified to incorporate RBD mutations corresponding to six VoCs, including strains that emerged in the United Kingdom (B.1.1.7), Italy (MB-61), South Africa (B.1.351), Brazil (P.1), India (B.1.617.1) and California (B.1.427/429) (See Supplementary Table S1 for sequences). The two IgGs (15033-7 and 15036) and two D-Fc-Fs (33-7:33-7 and 33-7:33-6) were assayed against the pseudovirus panel (Figure 5) and IC $_{50}$ values were calculated as a measure of potency (Table 2)

IgG 15033-7 was highly effective against WT (Figure 5A, $\mathrm{IC}_{50}=16$ ng/mL), B.1.1.7 (Figure 5B, $\mathrm{IC}_{50}=20 \mathrm{ng} / \mathrm{mL}$ ), B.1.617.1 (Figure 5C, $\mathrm{IC}_{50}=32 \mathrm{ng} / \mathrm{mL}$ ) and B.1.427/429 
(Figure 5D, $\left.\mathrm{IC}_{50}=20 \mathrm{ng} / \mathrm{mL}\right)$; moderately effective against MB-61 (Figure 5E, $\mathrm{IC}_{50}=160$ $\mathrm{ng} / \mathrm{mL}$ ); and ineffective against B.1.351 (Figure 5F, $\mathrm{IC}_{50}=680 \mathrm{ng} / \mathrm{mL}$ ) and P.1 (Figure 5G, $\left.\mathrm{IC}_{50}=1600 \mathrm{ng} / \mathrm{mL}\right) . \mathrm{IgG} 15036$ exhibited a similar pattern of activities, but in general, was less potent than $\mathrm{IgG}$ 15033-7. The mono-paratopic, tetravalent D-Fc-F 33-7:33-7 was more potent against the five variants that were neutralized by the IgGs - WT, B.1.1.7, B.1.617.1, B.1.427/429 and MB-61 (Figure 5A-E, IC50 = 9-46 ng/mL) - but it also was ineffective against the two variants that resisted the IgGs - B.1.351 and P.1 (Figure 5F-G, IC I0 $_{5}=2100$ or $550 \mathrm{ng} / \mathrm{mL}$, respectively). In contrast, the bi-paratopic, tetravalent D-Fc-F 33-7:36 was extremely potent against the entire pseudovirus panel $\left(\mathrm{IC}_{50}<10 \mathrm{ng} / \mathrm{mL}\right)$ and was the most potent agent in every case (Table 2). Most dramatically, D-Fc-F 33-7:36 was extremely potent even against the variants that resisted the IgGs and D-Fc-F 33-7:33-7, and these assays showed >100-fold enhancements in some cases. Indeed, the $\mathrm{IC}_{50}$ values for $\mathrm{D}-\mathrm{Fc}-\mathrm{F}$ 33-7:36 against five of the seven pseudoviruses were virtually identical, suggesting that we may have reached the limits of the dynamic range for this assay and some potencies were underestimated.

Finally, and most importantly, we assessed the neutralization potency of D-Fc-F 33-7:36 in cell-based assays with authentic infectious virus in two independent laboratories. At Washington University in the USA, we used a panel of five chimeric viruses with S-protein variants representing diverse VoCs and observed extremely potent neutralization in all cases $\left(\mathrm{IC}_{50}=1.5-7.2 \mathrm{ng} / \mathrm{mL}\right.$, Figure 6A). At the University of Brescia in Italy, we assessed activity against the currently dominant Delta variant and the highly recalcitrant Gamma variant with authentic virus, and we again observed extremely high potencies $\left(\mathrm{IC}_{50}=8.5\right.$ or $12 \mathrm{ng} / \mathrm{mL}$, respectively, Figure 6B). Taken together, these results confirmed that the bi-paratopic tetravalent D-Fc-F 33-7:36 is an extremely potent $\mathrm{nAb}$ for inhibition of SARS-CoV-2 infection with broad coverage against $\mathrm{VoCs}$, including those that are resistant to approved $\mathrm{nAb}$ therapeutics.

\section{Discussion}

Emergence of VoCs that resist approved nAbs (Hoffmann et al., 2021; Wang et al., 2021), as well as convalescent plasma and vaccine sera (Wall et al., 2021; Zhou et al., 2021), highlight the need for alternative therapeutics to meet this challenge. Modular and highly facile frameworks can fulfill this role as potential frontline therapies capable of neutralizing emerging VoCs and those that will emerge in the future. In particular, the E484K mutation found in the 
RBDs of Beta and Gamma VoCs - and also in the RBD of the Omicron variant (Bernasconi et al.) - impairs neutralization by bamlanivimab (Wang et al., 2021) and casirivimab (Kim et al., 2021; Wang et al., 2021), and the currently dominant Delta VoC also resists these nAbs to varying degrees (Planas et al., 2021).

The trimeric structure of the SARS-CoV-2 S-protein represents a significant vulnerability that can be exploited to enhance the potency of nAbs with advanced antibody engineering technologies. Numerous structural studies have shown that highly potent neutralizing IgGs take advantage of their two arms to bind simultaneously to two identical epitopes on the RBD, and bivalent binding enhances affinity and consequent potency of neutralization (Einav et al., 2019; Yan et al., 2021). We recently showed that fusing additional Fabs to a neutralizing IgG enhanced potency further and we also observed a concomitant improvement in neutralization of a VOC that resisted the IgG (Miersch et al., 2021). Moreover, structural studies of a tetravalent $\mathrm{nAb}$ in complex with the S-protein ECD confirmed that the two arms of the IgG bind simultaneously to two epitopes on the RBD, and intriguingly, suggested that a third arm can engage additional epitopes, within the same trimer or potentially a different trimer. These findings provide a molecular mechanism to explain the enhanced potency and breadth of coverage.

Here, we report a major advance in antibody engineering with a novel format that provides the crucial advantage of enabling rapid and facile combination of two distinct paratopes in a tetravalent $\mathrm{nAb}$ that retains the favorable biophysical properties of conventional IgG drugs. We started the engineering process by converting our potent neutralizing IgG 15033-7 (Figure 1A) to a D-Fc format (Figure 1B), which enabled modular attachment of additional Fabs at the C-terminus to produce tetravalent D-Fc-F proteins (Figure 1C). Importantly, the modular design strategy allowed for facile production of either the mono-paratopic D-Fc-F 33-7:33-7 or the biparatopic D-Fc-F 33-7:36, and both proteins proved to be comparable to IgGs in terms of biophysical properties (Figure 4). However, the tetravalent nAbs proved to be more potent than either IgG in neutralization assays with a panel of pseudoviruses representing SARC-CoV-2 VoCs (Figure 5). Most importantly, the bi-paratopic D-Fc-F 33-7:36 exhibited potent and broad neutralization of live viruses representing diverse VoCs, confirming that this tetravalent format represents an extremely promising means for the development of next-generation nAbs for the treatment of COVID-19. 
Critically, our results revealed the value of bi-paratopic design, as D-Fc-F 33-7:36 was extremely potent against every $\mathrm{VoC}$ tested to date, including those that resisted both IgGs and even the mono-paratopic D-Fc-F 33-7:33-7. These results were not necessarily expected, given that the epitopes of nAbs 15033-7 and 15036 presumably overlap and exhibit similar activity patterns in the pseudovirus neutralization assays (Figure 5). Nonetheless, the two paratopes function differently in the tetravalent D-Fc-F context, as evidenced by the dramatic potency and breadth of coverage exhibited by D-Fc-F 33-7:36 compared with D-Fc-F 33-7:33-7. While the structural basis for the synergy between the two paratopes in D-Fc-F 33-7:36 remains to be determined, these results unequivocally establish the bi-paratopic, tetravalent D-Fc-F format as a powerful platform for next generation drug design to tackle SARS-CoV-2 and perhaps other viruses.

Indeed, our approach is truly agnostic and generally applicable to SARS-CoV-2 and to other viruses with similar construction. Importantly, a priori knowledge of structural information is not required to enable rapid testing of numerous paratope pairs in a high-throughput manner. We and other groups have already identified hundreds of nAbs targeting diverse neutralizing epitopes on the SARS-CoV-2 RBD and other regions of the S-protein (Cao et al., 2020b; Hansen et al., 2020; Liu et al., 2020; Miersch et al., 2021; Rogers et al., 2020; Shi et al., 2020; Wan et al., 2020; Wec et al., 2020), including broadly neutralizing nAbs (Garrett Rappazzo et al., 2021). Our D-Fc-F format allows modular combination of virtually any Fab with D-Fc 15033-7, thus enabling the facile production of hundreds of tetravalent nAbs that can tested systematically to develop the best possible frontline treatment for COVID-19 that can treat emerging VoCs and those that will emerge in the future. 


\section{Acknowledgments}

We thank Dr. James Rini for generously providing biotinylated S-protein and RBD.

\section{Author Contributions}

'Shane Miersch Conceptualization, Methodology, Investigation, Supervision, Writing - Original Draft, Writing - Review \& Editing, Visualization, Validation, Project administration

Reza Saberianfar Methodology, Investigation

Chao Chen Investigation

Nitin Sharma Investigation

Gaya K. Amarasinghe Investigation

Arnaldo Caruso Investigation

Francesca Caccuri Investigation

Alberto Zani Investigation

Giuseppe Novelli Investigation

*\$Sachdev Sidhu Conceptualization, Writing - Original Draft, Supervision, Funding acquisition

\section{Declaration of Interests}

S.M and S.S.S. are inventors on a patent application describing anti-SARS-CoV-2 antibodies and multi-valent antibody formats.

\section{Funding}

This study was partially supported with grants from: Canadian Institutes of Health Operating Grant COVID-19 Rapid Research Funding Opportunity OV3-170649, Emergent Ventures / Thistledown Foundation FAST Grant, Emergent Ventures/The Mercatus Center FAST (\#2161 and \#2189), Temerty Foundation Knowledge Translation Grant - Novel Antibody Tools for COVID-19, Infrastructure was supported by a Canada Foundation for Innovation Infrastructure and Operating Grant \#IOF-33363 as well as with grants by Rome Foundation (Italy, Prot 317A / I) 592, Italian Ministry of University and Research (FISR2020IP_03161) and Regione Lazio to 
bioRxiv preprint doi: https://doi.org/10.1101/2021.11.02.466984; this version posted December 9, 2021. The copyright holder for this preprint

(which was not certified by peer review) is the author/funder, who has granted bioRxiv a license to display the preprint in perpetuity. It is made available under aCC-BY-NC 4.0 International license.

GN. And by the United States National Institute of Health grants (R01AI161374, R01AI143292, and P01AI120943). 


\section{Figures and Figure Legends}

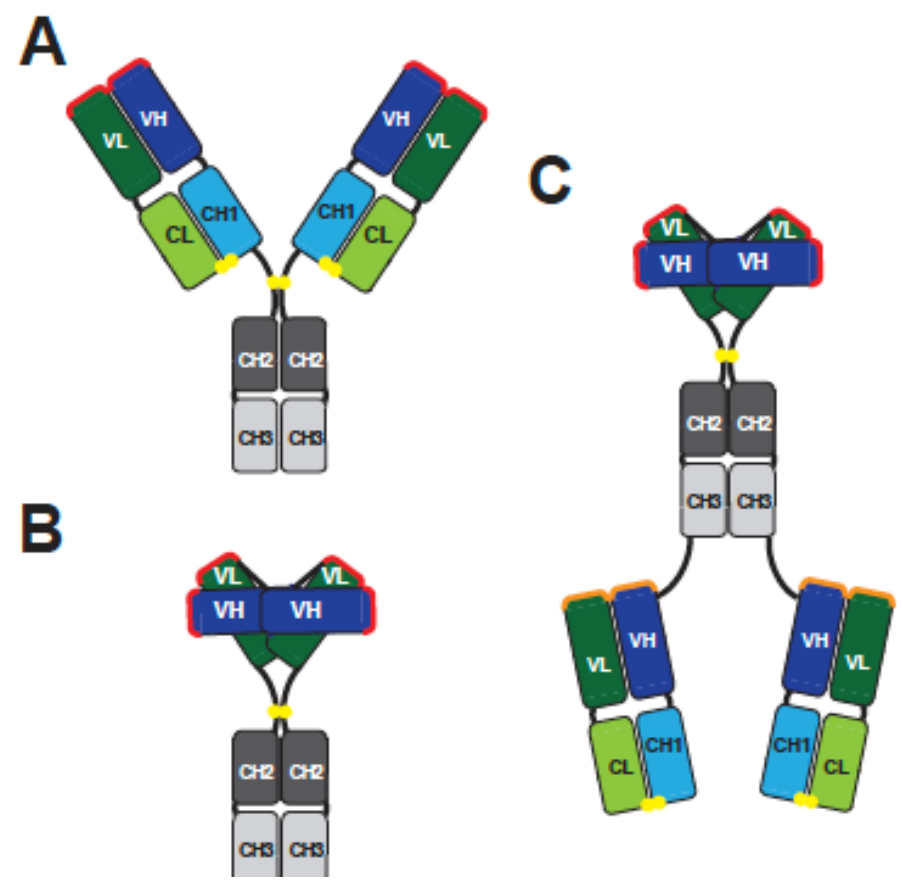

Figure 1. Antibody formats. Schematics are shown for (A) bivalent IgG, (B) bivalent diabodyFc (D-Fc), and (C) bi-paratopic tetravalent diabody-Fc-Fab (D-FcF) formats. The paratopes in the $\operatorname{IgG}$ and D-Fc molecules are shown in red. In the D-Fc-F molecule, the diabody paratopes are shown in red and the Fab paratopes are shown in orange. Linkers are shown in black and intermolecular disulfide bonds are shown as yellow spheres. The

domains are labeled and colored as follows: Fc, grey $(\mathrm{CH} 2$, dark; $\mathrm{CH} 3$, light); Fab heavy chain, blue (VH, dark; CH1, light); light chain, green (VL, dark; CL, light). 

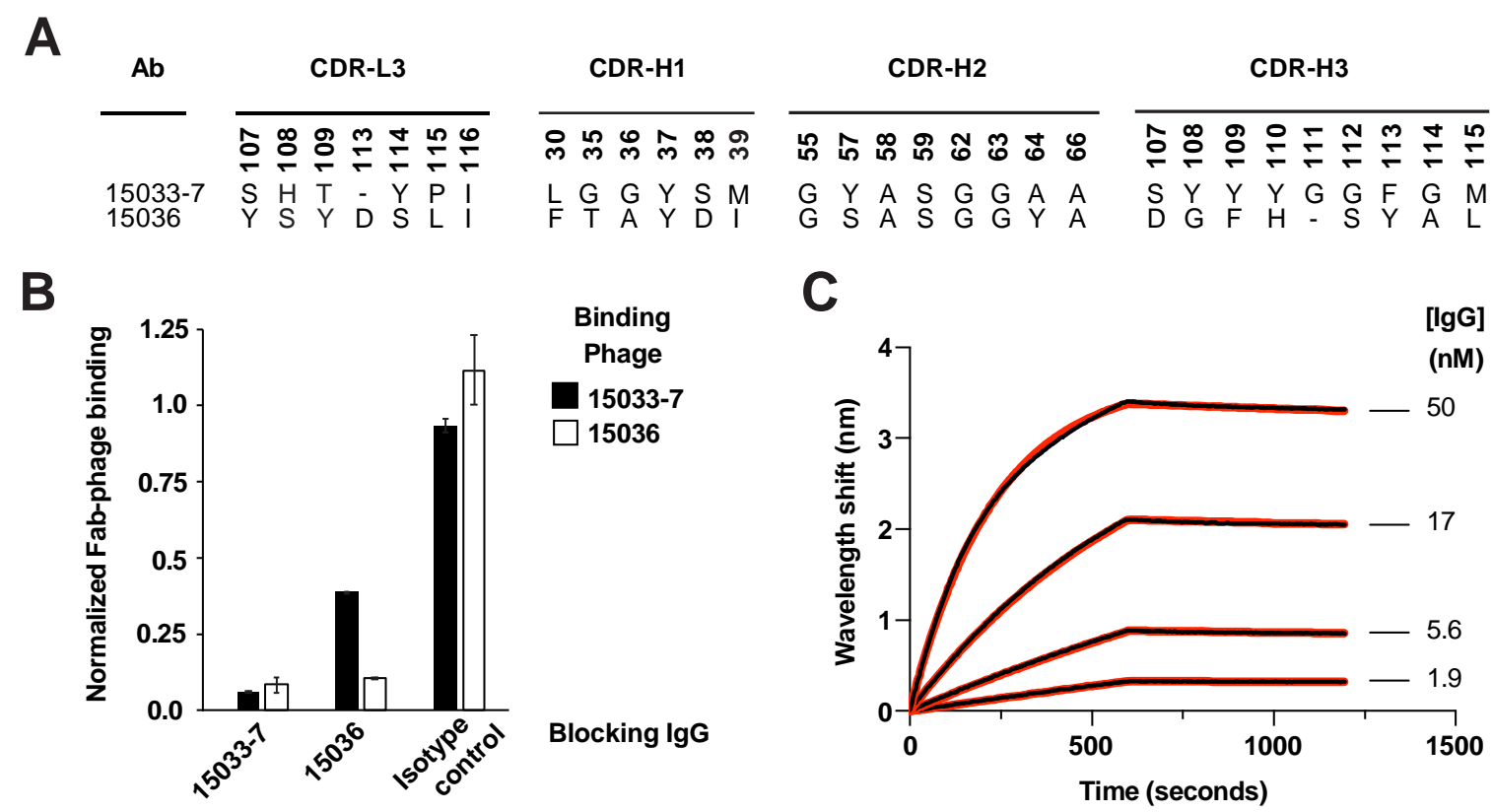

C

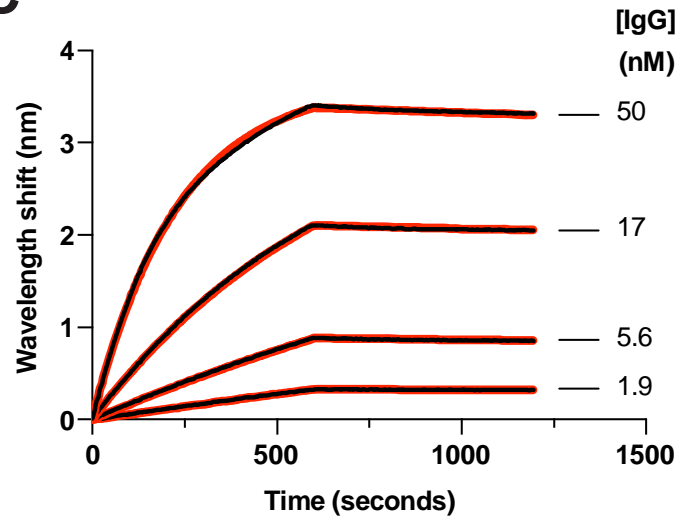

Figure 2. Characterization of antibody 15036. (A) CDR sequences of Abs 15033-7 and 15036. Positions are numbered according to the IMGT nomenclature (Lefranc et al., 2003). Only positions that were diversified in the Fab-phage library are shown. (B) Phage ELISAs for phagedisplayed Fab 15033-7 (black bars) or Fab 15036 (white bars) binding to immobilized RBD in the presence of $250 \mathrm{nM}$ blocking IgG 15033-7, 150336, or an isotype control. The binding signal was normalized to the signal in the absence of blocking IgG. (C) BLI sensor traces (black) for IgG 15036 binding to immobilized S-protein ECD trimer. Indicated concentrations of IgG 15036 were allowed to bind for 600 seconds and dissociation was monitored for an additional 600 seconds. The curves were globally fit (red) to a 1:1 binding model and derived binding constants are shown in Table 1. 

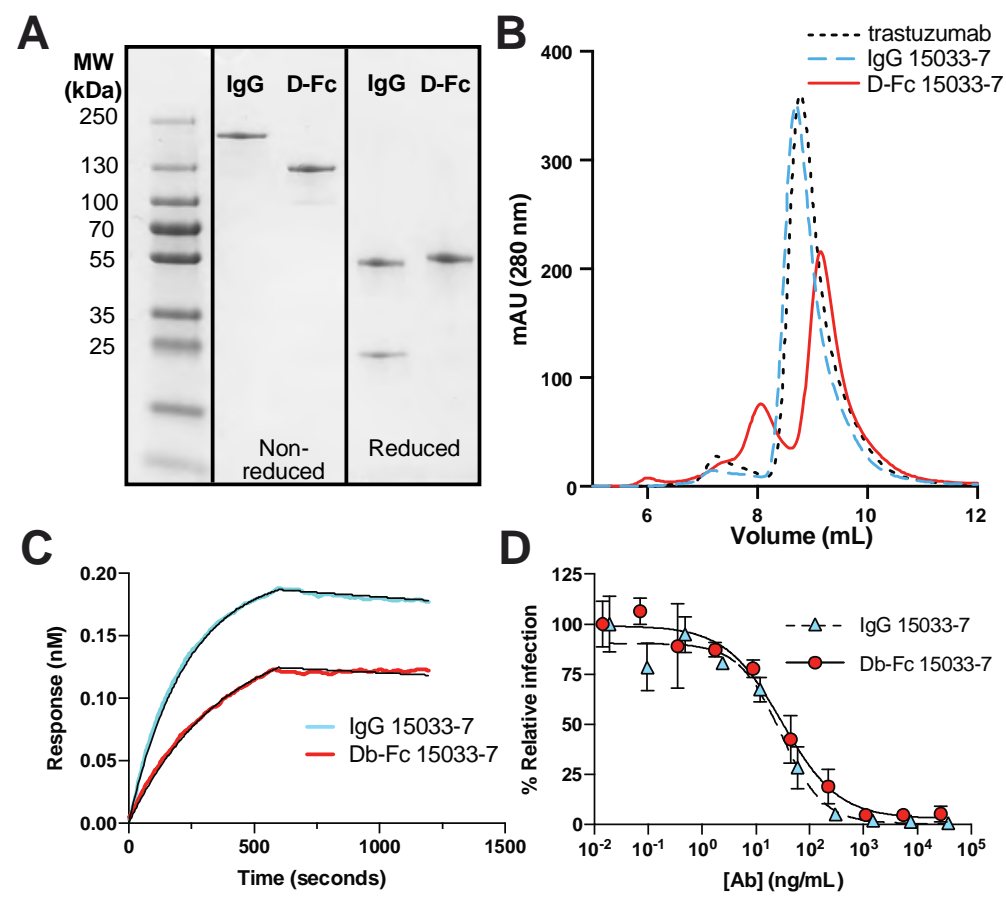

Figure 3. Characterization of D-Fc 15033-7. (A) SDS-PAGE analysis of $\mathrm{IgG}$ and $\mathrm{D}-\mathrm{Fc}$ versions of $\mathrm{Ab}$ 15033-7 under non-reducing (left) or reducing conditions (right). (B) Analytical gel filtration SEC of IgG 15033-7 (dashed blue), D-Fc 15033-7 (solid red), and trastuzumab IgG (dotted black). (C) BLI sensor traces for $5 \mathrm{nM}$ IgG $15033-7$ (blue) or D-Fc 15033-7 (red) binding to immobilized S-protein

ECD trimer. Abs were allowed to bind for 600 seconds, and dissociation was monitored for an additional 600 seconds. Traces and curve fits (black) for the complete analysis at various concentrations are shown in Supplementary Figure S1 and the derived binding constants are shown in Table 1. (D) Neutralization of pseudovirus by IgG 15033-7 (blue triangles, dashed line) or D-Fc 15033-7 (red circles, solid line). Pseudovirus was generated with S-protein from the original strain isolated in Wuhan. 

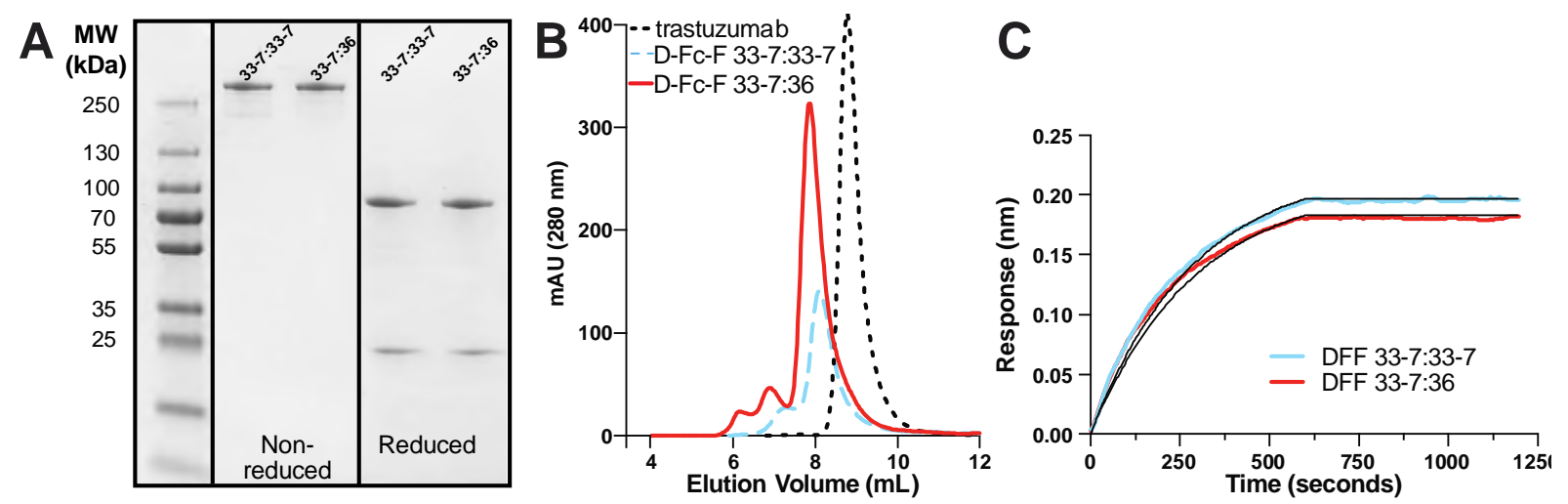

Figure 4. Characterization of D-Fc-F proteins. (A) SDS-PAGE analysis of D-Fc-F 33-7:33-7 and D-Fc-F 33-7:36 under non-reducing (left) or reducing conditions (right). (B) Analytical gel filtration SEC of D-Fc-F 33-7:33-7 (dashed blue), D-Fc-F 33-7:36 (solid red), and trastuzumab IgG (dotted black). (C) BLI sensor traces for 5 nM D-Fc-F 33-7:33-7 (blue) and D-Fc-F 33-7:36 (red) binding to immobilized S-protein ECD trimer. Abs were allowed to bind for 600 seconds, and dissociation was monitored for an additional 600 seconds. Traces and curve fits (black) for the complete analysis at various concentrations are shown in Supplementary Figure S1 and the derived binding constants are shown in Table 1. 


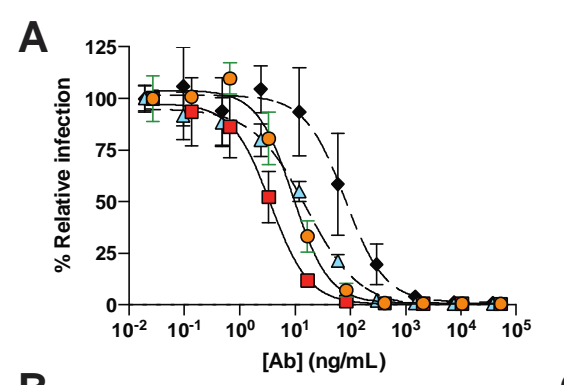

B

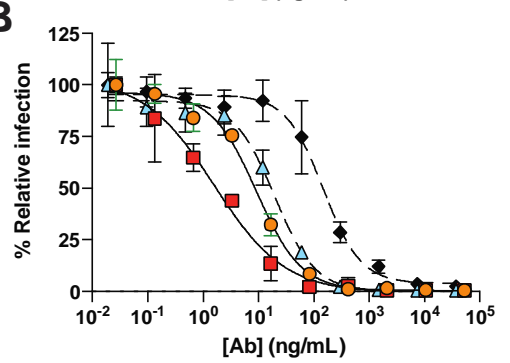

D

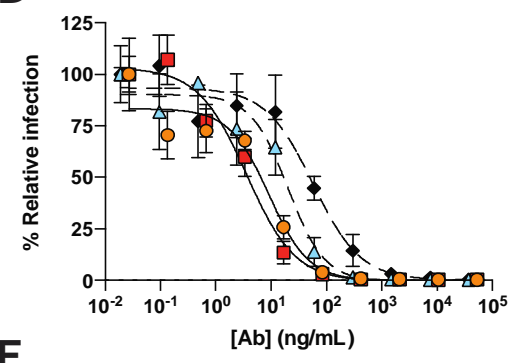

$\mathbf{F}$

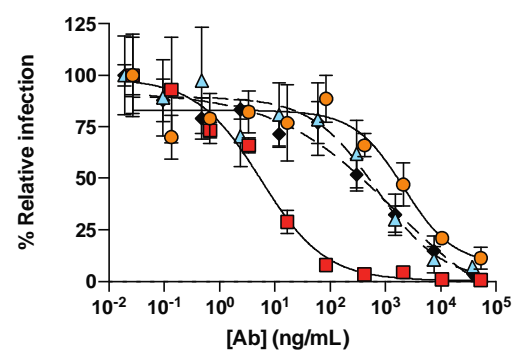

- $-\Delta^{-}-\lg \mathrm{g} 15033-7$

$-\diamond-\lg G 15036$

——D-Fc-F 33:7:33-7

$\longrightarrow$ D-Fc-F 33-7:36

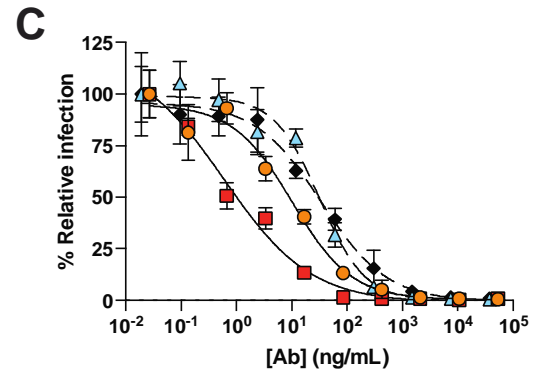

E
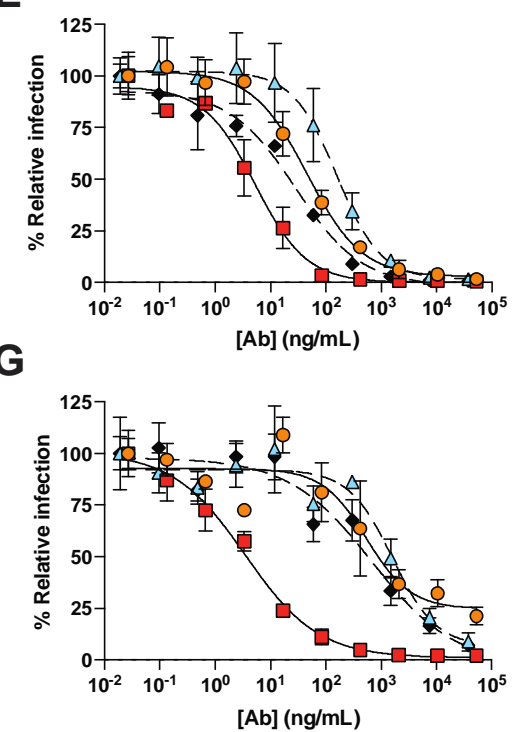

Figure 5. Neutralization of SARS-CoV-2 pseudoviruses.

Neutralization assays were conducted with HIV-gagbased, lentivirus-like particles pseudotyped with the following SARS-CoV-2 S-proteins:

(A) original strain from Wuhan, (B) Alpha (B.1.1.7) from the United Kingdom, (C) Kappa (B.1.617.1) from India, (D) Epsilon (B.1.427/429) from California, (E) MB-61 from Italy, (F) Beta (B.1.351) from South Africa, and (G) Gamma (P.1) from Brazil. The following nAbs were tested: IgG 15033-7 (cyan triangles, dashed lines), IgG 15036 (black diamonds, dashed lines), D-Fc-F 33-7:33-7 (orange

circles, solid lines), and D-Fc-F 33-7:36 (red squares, solid lines). The pseudovirus was pretreated with serial dilutions of nAb and infection of HEK293T cells stably expressing human ACE2 was measured relative to untreated control. Samples were run in duplicate, and results are representative of two independent experiments. Error bars indicate standard error of the mean. $\mathrm{IC}_{50}$ values were calculated from fit curves and are shown in Table 2. 


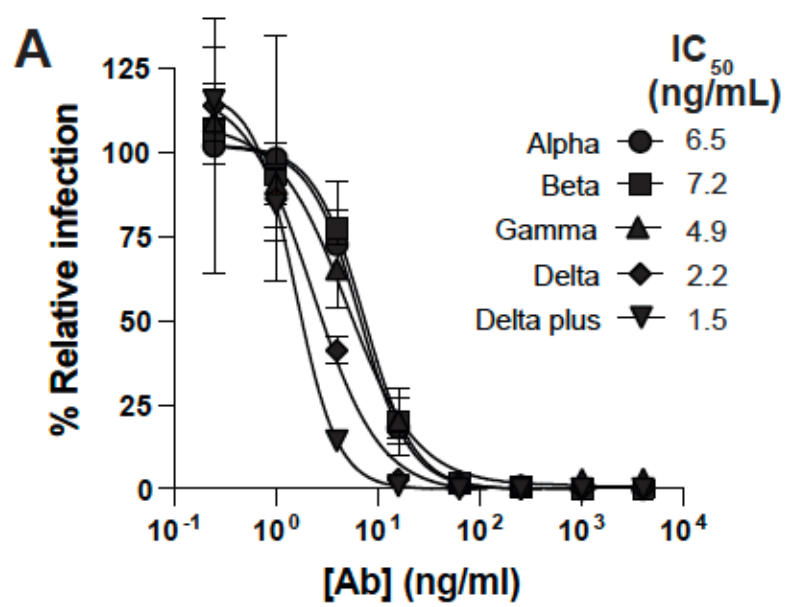

Figure 6. Neutralization of SARS-CoV-2

B

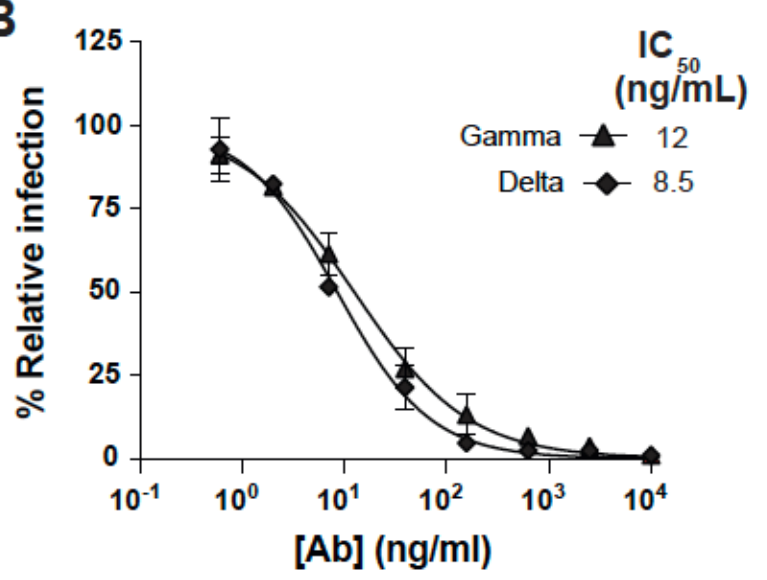

\section{variants by D-Fc-F 33-7:36. (A)}

Neutralization of chimeric virus variants. A focus reduction test was used to evaluate infection of Vero E6 cells following exposure to chimeric virus variants preincubated with serial dilutions of D-Fc-F 33-7:36. Results shown are representative of two independent experiments. Neutralization of authentic isolates of virus variants. A microneutralization assay was used to evaluate infection of Vero E6 cells following exposure to virus variants preincubated with serial dilutions of D-Fc-F 33-7:36. In both cases, samples were run in duplicate and normalized to infection in the absence of antibody with error bars shown as the standard deviation of the mean $\%$

relative infection values. Plots of $\mathrm{nAb}$ concentration versus relative infection for each were fit to estimate $\mathrm{IC}_{50}$ values shown in the legends. 
Table 1 - Summary of antibody characteristics

\begin{tabular}{|c|c|c|c|c|c|c|c|c|}
\hline \multirow[b]{2}{*}{ nAb } & \multicolumn{3}{|c|}{ Binding constants $^{a}$} & \multicolumn{2}{|c|}{$\begin{array}{c}\text { Pseudovirus } \\
\text { inhibition }^{b}\end{array}$} & \multicolumn{2}{|c|}{ SEC analysis $^{c}$} & \multirow[b]{2}{*}{$\begin{array}{l}\text { Yield }^{d} \\
\text { (mg/L) }\end{array}$} \\
\hline & $\begin{array}{c}k_{o n} \\
\left(10^{5} M^{-1} s^{-1}\right)\end{array}$ & $\begin{array}{c}\mathbf{K}_{\text {off }} \\
\left(10^{-5} \mathrm{~s}^{-1}\right)\end{array}$ & $\begin{array}{c}\text { Apparent } \\
\mathrm{K}_{\mathrm{D}}(\mathrm{pM})\end{array}$ & $\begin{array}{c}\mathrm{IC}_{50} \\
(\mathbf{n g} / \mathbf{m L})\end{array}$ & $\begin{array}{l}\mathrm{IC}_{50} \\
\text { (pM) }\end{array}$ & $\begin{array}{c}\text { SEC } \\
\text { Elution } \\
\text { volume } \\
(\mathrm{mL})\end{array}$ & $\begin{array}{c}\text { Mono } \\
\text { dispersity } \\
\text { (\%) }\end{array}$ & \\
\hline Trastuzumab & - & - & - & - & - & 8.7 & 92 & 303 \\
\hline $\lg G 15033-7$ & 9.1 & 6.4 & 70 & 16 & 2.4 & 8.7 & 95 & 165 \\
\hline $\lg G 15036$ & 6.2 & 14 & 220 & 80 & 12 & 8.3 & 91 & 167 \\
\hline D-Fc 15033-7 & 5.2 & 8.5 & 160 & 30 & 3.3 & 9.3 & 71 & 88 \\
\hline $\begin{array}{l}\text { D-FC-F 33- } \\
7: 33-7\end{array}$ & 7.8 & $<0.1$ & $<1$ & 9.2 & 1.9 & 8 & 80 & 190 \\
\hline $\begin{array}{l}\text { D-Fc-F 33- } \\
7: 36\end{array}$ & 8.0 & $<0.1$ & $<1$ & 3.6 & 0.8 & 7.9 & 81 & 189 \\
\hline
\end{tabular}

${ }^{a}$ Binding kinetics were measured by BLI with the immobilized S-protein ECD trimer and serial dilutions of nAb (Figure 2C, 3C, 4C, S1)

${ }^{b}$ Calculated from neutralization assays with pseudovirus displaying the S-protein of the original SARS-CoV-2 strain isolated in Wuhan, China (Figure 5)

${ }^{\circ}$ Calculated from gel filtration SEC (Figure 3B, 4B)

${ }^{d}$ Proteins were expressed in Expi293 cells and purified by Protein-A affinity chromatography (Figure 3A, 4A)

Table 2 - Summary of antibody $\mathrm{IC}_{50}$ values

\begin{tabular}{|c|c|c|c|c|c|c|}
\hline \multicolumn{3}{|c|}{ Pseudovirus $^{\mathrm{a}}$} & \multicolumn{4}{|c|}{$\left.n A b I C_{50}(n g / m L)\right)^{b}$} \\
\hline Origin & PANGO ID & Greek ID & IgG 15033-7 & $\lg G 15036$ & $\begin{array}{c}\text { D-Fc-F } \\
33-7: 33-7\end{array}$ & $\begin{array}{c}\text { D-Fc-F } \\
33-7: 36\end{array}$ \\
\hline Wuhan & - & - & 16 & 80 & 9.2 & 3.6 \\
\hline Italy & MB-61 & - & 160 & 28 & 46 & 5.3 \\
\hline UK & B.1.1.7 & Alpha & 20 & 150 & 9.2 & 1.6 \\
\hline SA & B.1.351 & Beta & 680 & 1400 & 2100 & 5.6 \\
\hline Manaus & P.1 & Gamma & 1600 & 680 & 550 & 3.5 \\
\hline California & P.1.427/429 & Epsilon & 20 & 57 & 9.1 & 3.6 \\
\hline India & B.1.617.1 & Kappa & 32 & 34 & 10 & 0.6 \\
\hline
\end{tabular}

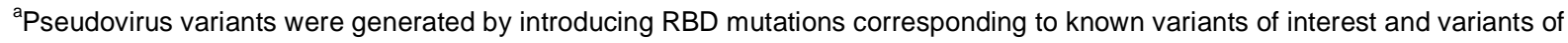
concern (Figure S2) to the plasmid encoding S-protein (original Wuhan strain) and used for pseudotyping.

${ }^{b}$ Values obtained by luminescent pseudovirus infection assay following exposure of ACE2-HEK293 cells to pseudovirus preincubated with serial dilutions of antibody. 
bioRxiv preprint doi: https://doi. org/10.1101/2021.11.02 466984 this version posted December 92021 . The copyright holder for this preprint (which was not certified by peer review) is the author/funder, who has granted bioRxiv a license to display the preprint in perpetuity. It is made available under aCC-BY-NC 4.0 International license.

\section{Materials}

\begin{tabular}{|c|c|c|}
\hline REAGENT OR RESOURCE & SOURCE & IDENTIFIER \\
\hline \multicolumn{3}{|l|}{ Antibodies } \\
\hline anti-M13-HRP & GE Healthcare & Cat\# GE27-9421-01 \\
\hline Anti-human kappa-HRP & Southern Biotech & Cat\# 2060-05 \\
\hline Phage displayed antibody library & Persson et al., 2013 & NA \\
\hline HRP-conjugated goat anti-human IgG & Abcam & Cat\# ab6858 \\
\hline \multicolumn{3}{|l|}{ Bacterial and virus strains } \\
\hline DH5 alpha & Thermofisher & Cat\# 18265017 \\
\hline Omnimax & Invitrogen & Cat\# C854003 \\
\hline $\mathrm{CJ} 236$ & Takara & Cat\# 3418 \\
\hline M13K07 & NEB & Cat\# N0315S \\
\hline 2019 n-CoV/USA_WA1/2020 & $\mathrm{CDC}$ & NA \\
\hline 2019-nCoV/Italy-Gamma & University of Brescia Medical School & NA \\
\hline 2019-nCoV/Italy-Delta & University of Brescia Medical School & NA \\
\hline \multicolumn{3}{|c|}{ Chemicals, peptides and recombinant proteins } \\
\hline SARS-CoV2 RBD & This paper & NA \\
\hline SARS-CoV2 spike & This paper & NA \\
\hline SARS-CoV2 spike & Abclonal & RP01283LQ \\
\hline Neutravidin & ThermoFisher & Cat\# 31000 \\
\hline Streptavidin HRP & ThermoFisher & Cat\# SNN1004 \\
\hline Biotin & Sigma & Cat\# B4501-5G \\
\hline hlgG1 15033-7 & This paper & NA \\
\hline hlgG1 15036 & This paper & NA \\
\hline D-Fc 15033-7 & This paper & NA \\
\hline D-Fc-F 33-7:33-7 & This paper & NA \\
\hline D-Fc-F 33-7:36 & This paper & NA \\
\hline rProtein A sepharose & GE Healthcare & Cat\# 17127903 \\
\hline Ni-NTA affinity resin & Qiagen & Cat\# 30230 \\
\hline Sypro orange & Sigma & Cat\# S5692 \\
\hline Bovine serum albumin & Bioshop & Cat\# ALB001.250 \\
\hline Histidine & Bioshop & HIS100.100 \\
\hline Sucrose & Bioshop & SUC700.500 \\
\hline Sodium chloride & Bioshop & Cat\# SOD001.10 \\
\hline Penicillin-streptomycin & Gibco & Cat\# 15070063 \\
\hline DMEM & Thermofisher & Cat\# 11995073 \\
\hline Fetal bovine serum & Gibco & Cat\# 12483-020 \\
\hline Lipofectamine 2000 & Thermofisher & Cat\# 11668027 \\
\hline Expi293F expression media & Thermofisher & Cat\# A1435102 \\
\hline 293Fectin reagent & Thermofisher & Cat\# 12347019 \\
\hline FectoPro transfection reagent & Polyplus Transfection & Cat\# 116-010 \\
\hline Opti-Mem media & Polyplus Transfection & Cat. \# 116-010 \\
\hline DPBS & Thermofisher & Cat. \#14190250 \\
\hline Protease inhibitor cocktail & Sigma & Cat. \#P-8849 \\
\hline Biotin ligase & This paper & NA \\
\hline
\end{tabular}




\begin{tabular}{|c|c|c|}
\hline NEBuilder HiFi DNA assembly cloning kit & NEB & Cat. \#E5520S \\
\hline \multicolumn{3}{|l|}{ Critical commercial assays } \\
\hline ONE-Glo EX Luciferase Assay System & Promega & Cat. \#8130 \\
\hline \multicolumn{3}{|l|}{ Experimental models: Cell lines } \\
\hline Vero E6 & ATCC & Cat. \#CRL-1586 \\
\hline HEK293Т & ATCC & Cat. \#CRL-3216 \\
\hline HEK293T-ACE2 & This manuscript & NA \\
\hline Expi293F & ThermoFisher & Cat. \#A14527 \\
\hline Freestyle 293-F & ThermoFisher & Cat. \#R79007 \\
\hline \multicolumn{3}{|l|}{ Experimental models: Organisms/Strains } \\
\hline Chimeric Alpha S-protein 2019 n-CoV/USA_WA1/2020 & Washington University & NA \\
\hline Chimeric Beta S-protein 2019 n-CoV/USA_WA1/2020 & Washington University & NA \\
\hline Chimeric Gamma S-protein 2019 n-CoV/USA_WA1/2020 & Washington University & NA \\
\hline Chimeric Kappa S-protein 2019 n-CoV/USA_WA1/2020 & Washington University & NA \\
\hline Chimeric Delta S-protein 2019 n-CoV/USA_WA1/2020 & Washington University & NA \\
\hline \multicolumn{3}{|l|}{ Oligonucleotides } \\
\hline Mutagenic oligonucleotides & IDT & Custom \\
\hline \multicolumn{3}{|l|}{ Recombinant DNA } \\
\hline hlgG1 15033-7 & This manuscript & NA \\
\hline hlgG1 15033-7 & This manuscript & NA \\
\hline D-Fc 15033-7 & This paper & NA \\
\hline D-Fc-F 33-7:33-7 & This paper & NA \\
\hline D-Fc-F 33-7:36 & This paper & NA \\
\hline HIV Gag vectors & Icosagen AS & N/A \\
\hline pNL4-3.luc.R-E & NIH AIDS Reagent Program & Cat. \#3418 \\
\hline PB-cmv-SARS-CoV-2 spike wt 1-1254 (C- $\Delta 19)$ & This Paper & NA \\
\hline \multicolumn{3}{|l|}{ Software and algorithms } \\
\hline Curvefitting: Prism 8.4 .3 & Graphpad & NA \\
\hline BLI data analysis: Octet Systems software 9.0 & Forte Bio & NA \\
\hline
\end{tabular}

\section{Methods}

\section{Cells}

Mammalian cells were maintained in humidified environments at $37{ }^{\circ} \mathrm{C}$ in $5 \% \mathrm{CO}_{2}$ in the indicated media. Vero E6 (ATCC, CRL-1586), HEK293T (ATCC, ACS-4500) and HEK293T cells stably overexpressing ACE2 were maintained at $37{ }^{\circ} \mathrm{C}$ in $5 \% \mathrm{CO}_{2}$ in $\mathrm{DMEM}$ containing $10 \%$ (vol/vol) FBS. Expi293F cells (ThermoFisher, A14528) were maintained at $37{ }^{\circ} \mathrm{C}$ in $8 \%$ $\mathrm{CO}_{2}$ in Expi293F expression media (ThermoFisher, A1435101). 


\section{Protein production and purification}

The SARS-CoV-2 S-protein ECD was obtained as a kind gift from Dr. James Rini, produced and purified as described (Miersch et al., 2021) or was obtained commercially (Abclonal, RPO1283LQ). Purified proteins were site-specifically biotinylated in a reaction with $200 \mu \mathrm{M}$ biotin, $500 \mu \mathrm{M}$ ATP, $500 \mu \mathrm{M} \mathrm{MgCl}_{2}, 30 \mu \mathrm{g} / \mathrm{mL}$ BirA, $0.1 \%$ (v/v) protease inhibitor cocktail and not more than $100 \mu \mathrm{M}$ of the protein-AviTag substrate. The reactions were incubated at $30{ }^{\circ} \mathrm{C}$ for 2 hours and biotinylated proteins were purified by size-exclusion chromatography.

\section{Ab production and purification}

IgG, D-Fc and D-Fc-F proteins were produced in Expi293F cells (ThermoFisher) by transient transfection, by diluting heavy and light chain expression plasmid DNA in OptiMem serum-free media (Gibco, 31985088) before the addition of and incubation with FectoPro (Polyplus Transfection, 10100007) for 10 minutes. For IgG and D-Fc-F production, equivalent amounts of plasmids encoding heavy chain or light chain were transfected, whereas for D-Fc production, a single construct encoding the D-Fc protein was transfected. Following addition of the DNA complex to Expi293F cells and a 5-day expression period, Abs were purified using rProtein-A Sepharose (GE Healthcare, 17127904), then buffer exchanged and concentrated using Amicon Ultra-15 Centrifugal Filter devices (Millipore, UFC805096). IgG and D-Fc proteins were stored in PBS (Gibco), and D-Fc-F proteins were stored in $10 \mathrm{mM}$ L-histidine, $0.9 \%$ sucrose, $140 \mathrm{mM}$ $\mathrm{NaCl}, \mathrm{pH} 6.0$.

\section{Phage display selections}

A synthetic, phage-displayed Fab library (Persson et al., 2013b) was selected for binding to biotinylated SARS-CoV-2 RBD, as described (Miersch et al., 2021). Individual clones from the same selected phage pool that previously yielded Ab 15033 were screened by phage ELISA to identify additional RBD-binding Fab-phage clones, including the progenitor of Ab 15036. The heavy chain of the 15036 progenitor was combined with a library of light chains with diversity in CDR-L3, and Fab 15036 was isolated following additional rounds of selection, as described (Miersch et al., 2021). 


\section{Phage ELISAs}

Phage ELISAs were performed, as described (Miersch et al., 2021). Briefly, 96-well Nunc Maxisorp (Sigma-Aldrich, M9410) plates were coated with neutravidin and blocked with PBS, $0.2 \%$ BSA. Biotinylated target protein was captured from solution by incubation in neutravidincoated and BSA-blocked wells for 15 minutes with shaking at room temperature. Wells were incubated for 1 hour with a saturating concentration of IgG in PBS, or with PBS alone, and subsequently, Fab-phage were added and incubated for 30 minutes. Plates were washed, incubated with an anti-M13 antibody-HRP conjugate (GE Healthcare, 27-9421-01), and developed with TMB substrate (KPL, KP-50-76-03), as described (Miersch et al., 2017).

\section{Construction of genes encoding D-Fc and D-Fc-F proteins}

DNA fragments encoding heavy (VH) and light chain (VL) variable domains, (terminating at $\operatorname{Ser}^{128}$ or Lys $^{127}$, respectively, IMGT numbering throughout (Lefranc et al., 2003)) were amplified by PCR from the IgG expression vectors. Db-Fc constructs were constructed using Gibson assembly (New England Biolabs, Ipswich, MA) to fuse these fragments with an intervening linker (sequence: GGGGS) with VH-linker-VL orientation, and then cloning the resultant insert into the pSCSTa mammalian expression vector, which resulted in the diabody being fused to the N-terminus of the hinge residue Asp $^{6}$ with an intervening linker (sequence: GGGGSGGGGS).. D-Fc-F constructs were assembled by fusing a Fab heavy chain to Fc residue Gly $^{129}$ at the C-terminus of the D-Fc with an intervening linker (sequence: GGGGSGGGGSGGGTG).

\section{Size exclusion chromatography}

Protein samples $(50 \mu \mathrm{g})$ were injected onto a TSKgel BioAssist G3SWxl column (Tosoh) fitted with a guard column using an NGC chromatography system and a C96 autosampler (Biorad). The column was preequilibrated in a PBS mobile phase and protein retention was monitored by absorbance at $215 \mathrm{~nm}$ during a $1.5 \mathrm{CV}$ isocratic elution in PBS.

\section{Biolayer interferometry}

The binding kinetics $\left(\mathrm{k}_{\mathrm{on}}\right.$ and $\left.\mathrm{k}_{\mathrm{off}}\right)$ and apparent affinity $\left(\mathrm{K}_{\mathrm{D}}\right)$ of Abs binding to the S-protein ECD were determined by BLI with an Octet HTX instrument (ForteBio) at $1000 \mathrm{rpm}$ and $25{ }^{\circ} \mathrm{C}$. 
Biotinylated S-protein ECD was captured on streptavidin biosensors from a $2 \mu \mathrm{g} / \mathrm{mL}$ solution to achieve a binding response of 0.4-0.6 nm and unoccupied sites were quenched with $100 \mu \mathrm{g} / \mathrm{mL}$ biotin. Abs were diluted with assay buffer (PBS, 1\% BSA, 0.05\% Tween 20), and $67 \mathrm{nM}$ of an irrelevant biotinylated protein of similar size was used as negative control. Following equilibration with assay buffer, loaded biosensors were dipped for 600 seconds into wells containing 3-fold serial dilutions of each $\mathrm{Ab}$ starting at $67 \mathrm{nM}$, and subsequently, were transferred back into assay buffer for 600 seconds. Binding response data were corrected by subtraction of response from a reference and were fitted with a 1:1 binding model using ForteBio Octet Systems software 9.0.

\section{Production of pseudoviruses}

HEK-293 cells (ATCC) were seeded in a 6-well plate at $3 \times 10^{5}$ cells/well in DMEM (ThermoFisher, 11995-065) supplemented with 10\% FBS and 1\% penicillin-streptomycin (Gibco,

15140122) and grown overnight at $37^{\circ} \mathrm{C}$ with $5 \% \mathrm{CO}_{2}$. HEK293 cells were co-transfected with $1 \mu \mathrm{g}$ pNL4-3.luc.R-E- plasmid (luciferase expressing HIV-1 with defective envelop protein) (NIH AIDS Reagent Program, ARP2128) and 0.06 $\mu \mathrm{g}$ CMV-promoter driven plasmid encoding the S-protein using Lipofectamine ${ }^{\mathrm{TM}} 2000$ transfection reagent (ThermoFisher, 11668027). Pseudovirus particles were harvested by collecting supernatant 48 hours after transfection and were filter sterilized (0.44 $\mu \mathrm{m}$, Millipore-Sigma, SLHA033SS).

\section{Pseudovirus infection assays}

HEK293T cells stably over-expressing full-length human ACE2 protein were seeded in 96-well white polystyrene microplates (Corning, CLS3610) at $3 \times 10^{4}$ cells/well in DMEM (10\% FBS and $1 \%$ penicillin-streptomycin) and were grown overnight at $37{ }^{\circ} \mathrm{C}$ with $5 \% \mathrm{CO}_{2}$. Pseudovirus particles were mixed with $\mathrm{Ab}$, incubated at room temperature for 10 minutes, and added to the cells. The cells were incubated at $37{ }^{\circ} \mathrm{C}$ with $5 \% \mathrm{CO}_{2}$, the medium was replaced with fresh DMEM (10\% FBS and 1\% penicillin-streptomycin) after 6 hours, and again every 24 hours up to 72 hours. To measure the luciferase signal (pseudovirus entry), DMEM was removed and DPBS (ThermoFisher) was added to cells before mixing with an equal volume of ONE-Glo ${ }^{\mathrm{TM}} \mathrm{EX}$ Luciferase Assay System (Promega, E8130). Relative luciferase units were measured using a 
BioTek Synergy Neo plate reader (BioTek Instruments Inc.). The data were analyzed by GraphPad Prism Version 8.4.3 (GraphPad Software, LLC).

\section{Authentic virus infection assays}

To evaluate neutralization of SARS-Cov-2 VoCs, chimeric S-protein variants were generated on the genetic background of the Washington strain (2019 n-CoV/USA_WA1/2020) as described (Chen et al., 2021). Neutralization of these infectious chimeric VoCs was evaluated using a focus reduction neutralization test and potency was estimated as described (Miersch et al., 2021).

For neutralization of authentic VoCs, clinical isolates were propagated, sequenced to verify identity, then used in a micro-neutralization assay as described (Caccuri et al., 2020). In brief, serial four-fold dilutions of antibody, starting from $10 \mu \mathrm{g} / \mathrm{mL}$, were pre-incubated with $10^{2}$ $\mathrm{TCID}_{50}$ of the virus per $100 \mu \mathrm{l}$ at $37^{\circ} \mathrm{C}$ for 1 hour. The antibody-virus mixture was transferred to 96-well tissue culture plates containing sub-confluent Vero E6 cells in duplicate and incubated at $37{ }^{\circ} \mathrm{C}$ and $5 \% \mathrm{CO}_{2}$ for 4 days before washing, fixation, staining and being read by a spectrophotometer at $590 \mathrm{~nm}$ as described (Manenti et al., 2020). 


\section{REFERENCES}

Baum, A., Fulton, B.O., Wloga, E., Copin, R., Pascal, K.E., Russo, V., Giordano, S., Lanza, K., Negron, N., Ni, M., et al. (2020). Antibody cocktail to SARS-CoV-2 spike protein prevents rapid mutational escape seen with individual antibodies. Science 369, 1014-1018.

Bernasconi, A., Pinoli, P., al Khalaf, R., Alfonsi, T., Canakoglu, A., Cilibrasi, L., and Ceri, S. Report on Omicron Spike mutations on epitopes and immunological/epidemiological/kinetics effects from literature - SARS-CoV-2 coronavirus / nCoV-2019 Genomic Epidemiology Virological.

Brouwer, P.J.M., Caniels, T.G., van der Straten, K., Snitselaar, J.L., Aldon, Y., Bangaru, S., Torres, J.L., Okba, N.M.A., Claireaux, M., Kerster, G., et al. (2020). Potent neutralizing antibodies from COVID-19 patients define multiple targets of vulnerability. Science (New York, N.Y.) 369, 643-650.

Cao, L., Goreshnik, I., Coventry, B., Case, J.B., Miller, L., Kozodoy, L., Chen, R.E., Carter, L., Walls, A.C., Park, Y.J., et al. (2020). De novo design of picomolar SARS-CoV-2 miniprotein inhibitors. Science 370 .

Connor, R.I., Chen, B.K., Choe, S., and Landau, N.R. (1995). Vpr Is Required for Efficient Replication of Human Immunodeficiency Virus Type-1 in Mononuclear Phagocytes. Virology 206, 935-944.

Einav, T., Yazdi, S., Coey, A., and Bjorkman, P.J. (2019). Harnessing Avidity: Quantifying the Entropic and Energetic Effects of Linker Length and Rigidity for Multivalent Binding of Antibodies to HIV-1. Cell Systems 9, 466-474.e7.

Garrett Rappazzo, C., Tse, L. v., Kaku, C.I., Wrapp, D., Sakharkar, M., Huang, D., Deveau, L.M., Yockachonis, T.J., Herbert, A.S., Battles, M.B., et al. (2021). Broad and potent activity against SARS-like viruses by an engineered human monoclonal antibody. Science (New York, N.Y.) 371, 823-829.

de Gasparo, R., Pedotti, M., Simonelli, L., Nickl, P., Muecksch, F., Cassaniti, I., Percivalle, E., C Lorenzi, J.C., Mazzola, F., Magrì, D., et al. (2020). Bispecific IgG neutralizes SARS-CoV-2 variants and prevents escape in mice. Nature 593.

Gottlieb, R.L., Nirula, A., Chen, P., Boscia, J., Heller, B., Morris, J., Huhn, G., Cardona, J., Mocherla, B., Stosor, V., et al. (2021). Effect of Bamlanivimab as Monotherapy or in Combination With Etesevimab on Viral Load in Patients With Mild to Moderate COVID-19: A Randomized Clinical Trial. JAMA 325, 632-644.

Greaney, A.J., Starr, T.N., Gilchuk, P., Zost, S.J., Binshtein, E., Loes, A.N., Hilton, S.K., Huddleston, J., Eguia, R., Crawford, K.H.D., et al. (2021). Complete Mapping of Mutations to the SARS-CoV-2 Spike Receptor-Binding Domain that Escape Antibody Recognition. Cell Host \& Microbe 29, 44-57.e9.

Hansen, J., Baum, A., Pascal, K.E., Russo, V., Giordano, S., Wloga, E., Fulton, B.O., Yan, Y., Koon, K., Patel, K., et al. (2020). Studies in humanized mice and convalescent humans yield a SARS-CoV-2 antibody cocktail. Science (New York, N.Y.) 369, 1010-1014.

Hart, T.K., Sellers, T.S., Maleeff, B.E., Eustis, S., Schwartz, L.W., Bugelski, P.J., Herzyk, D.J., Cook, R.M., Zia-Amirhosseini, P., Minthorn, E., et al. (2001). Preclinical efficacy and safety of mepolizumab (SB-240563), a humanized monoclonal antibody to IL-5, in cynomolgus monkeys. Journal of Allergy and Clinical Immunology 108, 250-257.

Hoffmann, M., Kleine-Weber, H., Schroeder, S., Mü, M.A., Drosten, C., and Pö, S. (2020). SARS-CoV-2 Cell Entry Depends on ACE2 and TMPRSS2 and Is Blocked by a Clinically Proven Protease Inhibitor. Cell 181, 271-280.e8. 
Hoffmann, M., Hofmann-Winkler, H., Krüger, N., Kempf, A., Nehlmeier, I., Graichen, L., Arora, P., Sidarovich, A., Moldenhauer, A.S., Winkler, M.S., et al. (2021). SARS-CoV-2 variant B.1.617 is resistant to bamlanivimab and evades antibodies induced by infection and vaccination. Cell Reports 36.

Hunt, A.C., Case, J.B., Park, Y.-J., Cao, L., Wu, K., Walls, A.C., Liu, Z., Bowen, J.E., Yeh, H.W., Saini, S., et al. (2021). Multivalent designed proteins protect against SARS-CoV-2 variants of concern. BioRxiv.

Jensen, B., Luebke, N., Feldt, T., Keitel, V., Brandenburger, T., Kindgen-Milles, D., Lutterbeck, M., Freise, N.F., Schoeler, D., Haas, R., et al. (2021). Emergence of the E484K mutation in SARS-COV-2-infected immunocompromised patients treated with bamlanivimab in Germany. The Lancet Regional Health - Europe 8, 100164.

Kayabolen, A., Akcan, U., Ozturan, D., Sarayloo, E., Nurtop, E., Ozer, B., Sahin, G.N., Dogan, O., Lack, N., Kaya, M., et al. (2021). Protein scaffold-based multimerization of soluble ACE2 efficiently blocks SARS-CoV-2 infection in vitro. BioRxiv 2021.01.04.425128.

Kim, Y.J., Jang, U.S., Soh, S.M., Lee, J.Y., and Lee, H.R. (2021). The Impact on Infectivity and Neutralization Efficiency of SARS-CoV-2 Lineage B.1.351 Pseudovirus. Viruses 13.

Klein, S., Cortese, M., Winter, S.L., Wachsmuth-Melm, M., Neufeldt, C.J., Cerikan, B., Stanifer, M.L., Boulant, S., Bartenschlager, R., and Chlanda, P. (2020). SARS-CoV-2 structure and replication characterized by in situ cryo-electron tomography. BioRxiv 2020.06.23.167064. McCallum, M., Bassi, J., Marco, A. de, Chen, A., Walls, A.C., Iulio, J. di, Tortorici, M.A., Navarro, M.-J., Silacci-Fregni, C., Saliba, C., et al. (2021). SARS-CoV-2 immune evasion by the B.1.427/B.1.429 variant of concern. Science 373, 648-654.

Miersch, S., Li, Z., Saberianfar, R., Ustav, M., Brett Case, J., Blazer, L., Chen, C., Ye, W., Pavlenco, A., Gorelik, M., et al. (2021). Tetravalent SARS-CoV-2 Neutralizing Antibodies Show Enhanced Potency and Resistance to Escape Mutations. Journal of Molecular Biology 433, 167177.

Persson, H., Ye, W., Wernimont, A., Adams, J.J., Koide, A., Koide, S., Lam, R., and Sidhu, S.S. (2013). CDR-H3 diversity is not required for antigen recognition by synthetic antibodies. Journal of Molecular Biology 425, 803-811.

Pinto, D., Park, Y.J., Beltramello, M., Walls, A.C., Tortorici, M.A., Bianchi, S., Jaconi, S., Culap, K., Zatta, F., de Marco, A., et al. (2020). Cross-neutralization of SARS-CoV-2 by a human monoclonal SARS-CoV antibody. Nature 2020 583:7815 583, 290-295.

Planas, D., Veyer, D., Baidaliuk, A., Staropoli, I., Guivel-Benhassine, F., Rajah, M.M., Planchais, C., Porrot, F., Robillard, N., Puech, J., et al. (2021). Reduced sensitivity of SARSCoV-2 variant Delta to antibody neutralization. Nature 2021 596:7871 596, 276-280.

Razonable, R.R., Pawlowski, C., O’Horo, J.C., Arndt, L.L., Arndt, R., Bierle, D.M., Borgen, M.D., Hanson, S.N., Hedin, M.C., Lenehan, P., et al. (2021). Casirivimab-Imdevimab treatment is associated with reduced rates of hospitalization among high-risk patients with mild to moderate coronavirus disease-19. EClinicalMedicine 40, 101102.

Tortorici, M.A., Beltramello, M., Lempp, F.A., Pinto, D., Dang, H. v., Rosen, L.E., McCallum, M., Bowen, J., Minola, A., Jaconi, S., et al. (2020). Ultrapotent human antibodies protect against SARS-CoV-2 challenge via multiple mechanisms. Science (New York, N.Y.) 370, 950-957. Wall, E.C., Wu, M., Harvey, R., Kelly, G., Warchal, S., Sawyer, C., Daniels, R., Hobson, P., Hatipoglu, E., Ngai, Y., et al. (2021). Neutralising antibody activity against SARS-CoV-2 VOCs B.1.617.2 and B.1.351 by BNT162b2 vaccination. Lancet (London, England) 397, 2331-2333. 
Walls, A.C., Park, Y.J., Tortorici, M.A., Wall, A., McGuire, A.T., and Veesler, D. (2020). Structure, Function, and Antigenicity of the SARS-CoV-2 Spike Glycoprotein. Cell 181, 281292.e6.

Walser, M., Rothenberger, S., Hurdiss, D.L., Schlegel, A., Calabro, V., Fontaine, S., Villemagne, D., Paladino, M., Hospodarsch, T., Neculcea, A., et al. (2021). Highly potent anti-SARS-CoV-2 multivalent DARPin therapeutic candidates. BioRxiv 2020.08.25.256339.

Wang, P., Nair, M.S., Liu, L., Iketani, S., Luo, Y., Guo, Y., Wang, M., Yu, J., Zhang, B., Kwong, P.D., et al. (2021). Antibody resistance of SARS-CoV-2 variants B.1.351 and B.1.1.7. Nature 2021 593:7857 593, 130-135.

Weinreich, D.M., Sivapalasingam, S., Norton, T., Ali, S., Gao, H., Bhore, R., Xiao, J., Hooper, A.T., Hamilton, J.D., Musser, B.J., et al. (2021). REGEN-COV Antibody Combination and Outcomes in Outpatients with Covid-19. New England Journal of Medicine.

Weisblum, Y., Schmidt, F., Zhang, F., DaSilva, J., Poston, D., Lorenzi, J.C.C., Muecksch, F., Rutkowska, M., Hoffmann, H.H., Michailidis, E., et al. (2020). Escape from neutralizing antibodies 1 by SARS-CoV-2 spike protein variants. ELife 9, 1.

Xu, J., Xu, K., Jung, S., Conte, A., Lieberman, J., Muecksch, F., Lorenzi, J.C.C., Park, S., Schmidt, F., Wang, Z., et al. (2021). Nanobodies from camelid mice and llamas neutralize SARS-CoV-2 variants. Nature 2021 595:7866 595, 278-282.

Yan, R., Wang, R., Ju, B., Yu, J., Zhang, Y., Liu, N., Wang, J., Zhang, Q., Chen, P., Zhou, B., et al. (2021). Structural basis for bivalent binding and inhibition of SARS-CoV-2 infection by human potent neutralizing antibodies. Cell Research 2021 31:5 31, 517-525.

Zhou, D., Dejnirattisai, W., Supasa, P., Liu, C., Mentzer, A.J., Ginn, H.M., Zhao, Y., Duyvesteyn, H.M.E., Tuekprakhon, A., Nutalai, R., et al. (2021). Evidence of escape of SARSCoV-2 variant B.1.351 from natural and vaccine-induced sera. Cell 184, 2348-2361.e6. 